\title{
Effect of Cd Dopant on Dielectric Properties of $\mathrm{CaCu}_{3} \mathrm{Ti}_{4} \mathrm{O}_{12}$
}

\author{
A. Onodera, M. Takesada, and S. Hiramatsu \\ Department of Physics, faculty of Science, Hokkaido University, Sapporo 060-0810 \\ Fax:+81-011-706-3583, e-mail: mt@phys.sci.hokudai.ac.jp
}

\begin{abstract}
The doping effect of $\mathrm{Cd}$ ions on the giant dielectric response in $\mathrm{Ca}_{1-x} \mathrm{Cd}_{x} \mathrm{Cu}_{3} \mathrm{Ti}_{4} \mathrm{O}_{12}$ ceramics with $x=0,0.01,0.03,0.05$ and 0.1 was studied in the frequency range of 10 $\mathrm{kHz}-1 \mathrm{MHz}$ over the temperature range of $300-850 \mathrm{~K}$. It is found that the chemical substitution of $\mathrm{Cd}$ ions at the $\mathrm{Ca}$ sites results in decrease in dielectric constant by $9 \%$ - 55\% for $\mathrm{Cd}$-doped $\mathrm{CaCu}_{3} \mathrm{Ti}_{4} \mathrm{O}_{12}$, at room temperature. Although the decrease in the dielectric constant was observed by $\mathrm{Cd}$ doping, no drastic suppression of dielectric response could be observed by Cd-doping. The dielectric anomaly was found at $T_{1}(727 \mathrm{~K}$ for $x=0.05)$, which suggests a phase transition. This $T_{1}$ decreases linearly with increasing $x . \mathrm{CdCu}_{3} \mathrm{Ti}_{4} \mathrm{O}_{12}$ is still a member of high-dielectric materials.
\end{abstract}

Key words: CCTO, dopant, high dielectric constant, oxide

\section{INTRODUCTION}

Giant dielectric response was discovered in the perovskite-related oxide $\mathrm{CaCu}_{3} \mathrm{Ti}_{4} \mathrm{O}_{12}$ (abbreviated as CCTO) over a wide temperature range of $100-600 \mathrm{~K}$ by Subramanian and coworkers.[1] This compound exhibits dielectric constants as high as $10^{4}$ at room temperature, although no ferroelectric phase transition has been reported until now. In the low temperature region, the dielectric constant decreases down to $10^{2}$ around $100 \mathrm{~K}$, accompanying with large dielectric dispersion.[2] Furthermore an antiferromagnetic phase transition was observed at $25 \mathrm{~K}$ by magnetic susceptibility and specific heat measurements.[3] Compared with typical perovskite-type ferroelectrics such as $\mathrm{BaTiO}_{3}$ and $\mathrm{PbTiO}_{3}$, the nature of this perovskite-related compound is very peculiar in exhibiting high dielectric constants over the wide range of temperature. The giant dielectric behavior seems to originate from an extrinsic origin. The extrinsic effects, such as the interfacial polarization effect [4], the internal boundary layer capacitance effect, and the grain boundary effect [5-10] have also been. Many experimental results suggest that an internal barrier layer capacitor (IBLC) model is responsible.[8, 11-13] However, the occurrence of the dielectric relaxations in both single crystals and ceramic samples indicates that the simple IBLC model is not the only possible explanation.[14] Zhu et al.[15] found recently that some $\mathrm{Cu}$ ions occupy the $\mathrm{Ca}$ sites, which may split the degeneracy and result in a metal-like behavior and enhance the dielectric responses.

The crystal structure of $\mathrm{CaCu}_{3} \mathrm{Ti}_{4} \mathrm{O}_{12}$ is cubic ( $\operatorname{Im} 3, a=7.3781 \AA$ ) at room temperature, where the unit cell is $2 \times 2 \times 2$ times the size of typical perovskite $\mathrm{ABO}_{3} \cdot[16]$ The $\mathrm{Ca}^{2+}$ ions occupy a body centered position in a doubled perovskite-type cubic cell, whereas the $\mathrm{Cu}^{2+}$ ions are located on the face and edge centers of the unit cell, as shown in Fig. 1. The $A \mathrm{Cu}_{3} \mathrm{Ti}_{4} \mathrm{O}_{12}$ $(A=\mathrm{Cd}, \mathrm{Bi}, \mathrm{Sr}, \mathrm{Na}$, rare-earth elements, or vacancy) series of compound were reported to have dielectric constants less than 4000.[17-19] Another series of isomorphous $A \mathrm{Cu}_{3} M_{4} \mathrm{O}_{12}$ $(M=\mathrm{Mn}, \mathrm{Ru}, \mathrm{Ge}, \mathrm{Cr}, \mathrm{Ga}, \mathrm{Nb}, \mathrm{Fe}, \mathrm{Sb}, \mathrm{Ta})$ offers dielectric constants below 1000.[11,17,20] Recent first-principles calculations reveal that CCTO provides dielectric constants only in the range 40-50.[21] Many researchers considered that the large dielectric response is not intrinsic, and should be extrinsic and related to the special microstructure.[22]

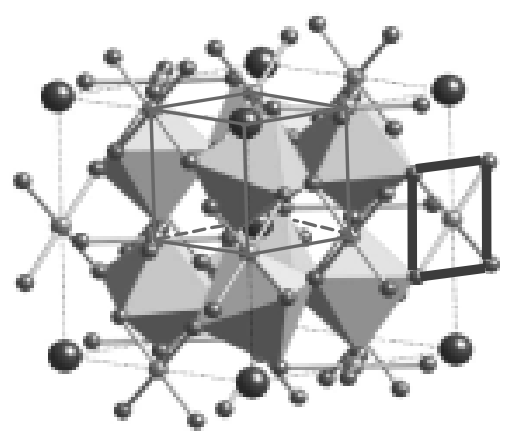

Figure 1 Crystal structure of $\mathrm{CaCu}_{3} \mathrm{Ti}_{4} \mathrm{O}_{12}$ oxide: $\mathrm{Ca}$ (large circle) at the corner and body centered position, $\mathrm{Cu}$ on the face and edge centers of the unit cell. Octahera are $\mathrm{TiO}_{6}$ perovskite units. Solid lines imdicate the unit cell of typical perovskite $\mathrm{ABO}_{3}$ structure and square $\mathrm{CuO}_{2}$ plane.

Due to its unusual perovskite-related structure, the dielectric properties of CCTO have attracted considerable attention in recent years. Recently a 
new dielectric anomaly was found at $732 \mathrm{~K}$ $\left(T_{1}\right)$.[23,24]. Although extensive works have been done to understand the anomalous dielectric behavior, the origin of the novel high dielectric response is still unclear. In this paper, we prepared Cd-doped CCTO and studied the role of $\mathrm{Cd}$ ions in $A \mathrm{Cu}_{3} \mathrm{Ti}_{4} \mathrm{O}_{12}$ structure, since the dielectric constant of isomorphous $\mathrm{CdCu}_{3} \mathrm{Ti}_{4} \mathrm{O}_{12}$ is only 409 at $100 \mathrm{kHz}$ and room temperature.[1]

\section{EXPERIMENTAL}

$\mathrm{CaCd}_{x} \mathrm{Cu}_{3-x} \mathrm{Ti}_{4} \mathrm{O}_{12}(x=0,0.01,0.03,0.05$, and 0.1$)$ ceramics were synthesized via the conventional solid-state reaction method using stoichiometric amounts of high-purity $\mathrm{CaCO}_{3}, \mathrm{CuO}, \mathrm{TiO}_{2}$, and $\mathrm{CdO}$. The mixed powders were calcined in air at $1273 \mathrm{~K}$ for $12 \mathrm{~h}$ and at $1373 \mathrm{~K}$ for $24 \mathrm{~h}$ with an intermediate grinding. The calcined samples were milled and pressed into pellets of $20 \mathrm{~mm}$ in diameter and about $1 \mathrm{~mm}$ in thickness. Then the pellets were sintered in air at $1373 \mathrm{~K}$ for $12 \mathrm{~h}$. X-ray powder diffraction data were recorded on an X-ray diffractometer with $\mathrm{MoK} \alpha$ radiation and a diffracted-beam graphite monochromator operated at 50 $\mathrm{kV}$ and $100 \mathrm{~mA}$. To measure the dielectric properties, silver electrodes were painted on the samples' surfaces. Dielectric constant and $\tan \delta$ data were collected by using HP-4274A and HP-4275A LCR meters in the temperature range of $300-850 \mathrm{~K}$.

\section{DOPING EFFECT ON DIELECTRIC CONSTANT}

$\mathrm{CdCu}_{3} \mathrm{Ti}_{4} \mathrm{O}_{12}$ has been reported to have a relative low dielectric constant, although it is isomorphous with CCTO : the room temperature dielectric constant of $\mathrm{CdCu}_{3} \mathrm{Ti}_{4} \mathrm{O}_{12}$ was reported to be $409(100 \mathrm{kHz})$, which is only $4 \%$ of that of CCTO [1]. The doping effect of $\mathrm{Cd}$ ions on the giant dielectric constant was studied in mixed $\mathrm{Ca}_{1-x} \mathrm{Cd}_{x} \mathrm{Cu}_{3} \mathrm{Ti}_{4} \mathrm{O}_{12}$ ceramics. Figures 2 and 3 show the temperature dependence of dielectric constant of $\mathrm{Ca}_{0.95} \mathrm{Cd}_{0.05} \mathrm{Cu}_{3} \mathrm{Ti}_{4} \mathrm{O}_{12}$ from room temperature to 850 $\mathrm{K}$ at the frequencies of $10 \mathrm{kHz}, 100 \mathrm{kHz}$ and $1 \mathrm{MHz}$.

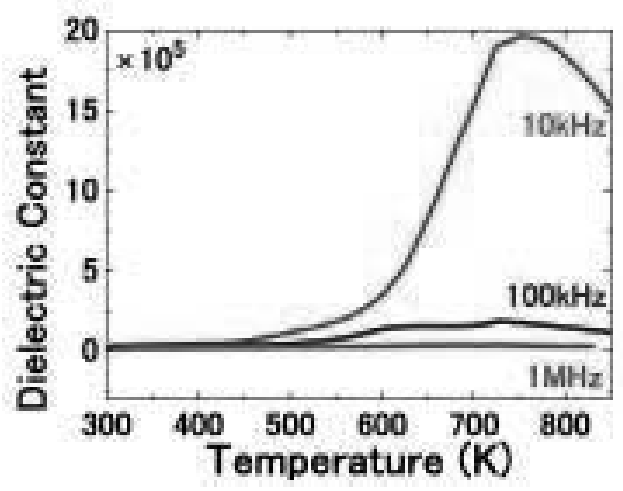

Figure 2. Temperature dependence of Cd-doped CCTO with $x=0.05$ at $10 \mathrm{kHz}, 100 \mathrm{kHz}$ and $1 \mathrm{MHz}$.

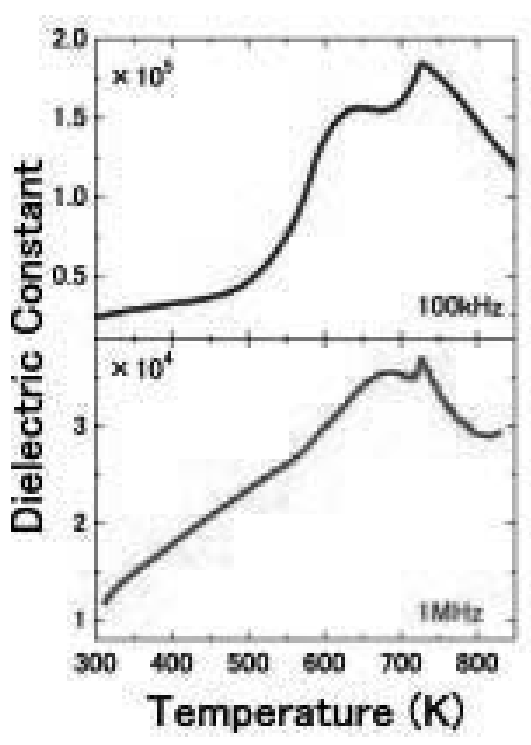

Figure 3. Expanded figures of dielectric constant of Cd-doped CCTO.

The value of dielectric constant is $4 \times 10^{4}$ at $350 \mathrm{~K}$, which is almost the same as those observed in pure CCTO. With increasing temperature, the dielectric constant increases monotonously and reaches to $6.6 \times$ $10^{5}$ at $600 \mathrm{~K}$. Above $600 \mathrm{~K}$, the dielectric constant increases rather rapidly, and exhibits a shoulder-like round anomaly around $630 \mathrm{~K}$ at $10 \mathrm{kHz}$. A new dielectric anomaly was found at $728 \mathrm{~K}\left(T_{1}\right)$, of which peak values are $1.8 \times 10^{6}$ at $10 \mathrm{kHz}, 1.7 \times 10^{5}$ at 100 $\mathrm{kHz}$ and $3.8 \times 10^{4}$ at $1 \mathrm{MHz}$. The dielectric evidence shows that Cd-doped CCTO undergoes a phase transition at $T_{1}$, as obsreved in pure CCTO.[24] The shoulder-like anomaly shifts from $630 \mathrm{~K}$ to $650 \mathrm{~K}$ with increasing frequency $(1 \mathrm{MHz})$. This shoulder-like behavior is coincident well with pure CCTO.[23] This dispersion has been observed in CCTO by Zhang et al.[25], Patterson et al.[26], and Choudhary et al. [27]. The molar ratio $(x)$ dependence of dielectric constant is shown in Fig. 4. The overall values decrease once with increasing $x$, and then turn to increase for the samples over $x=0.03$. The dielectric constant at $350 \mathrm{~K}$ is $8.3 \times 10^{4}$ for pure compound at $1 \mathrm{MHz}$, and shows a minimum $(\varepsilon$ $\sim 3 \times 10^{3}$ ) for $x=0.03$. However, it increases for the sample with $x=0.05\left(\varepsilon \sim 1.1 \times 10^{4}\right)$.

The Cd-doped samples have also high dielectric constant and a dielectric anomaly at $T_{1}$. The transition temperature $T_{1}$ shifts linearly from $732 \mathrm{~K}(x=0)$ to $727 \mathrm{~K}$ $(x=0.05)$ with increasing $x$ (Fig. 5). However, no drastic dielectric suppression could be observed by Cd-doping as shown in Fig. 6. This conclusion is consistent with a previous dielectric measurement of pure $\mathrm{CdCu}_{3} \mathrm{Ti}_{4} \mathrm{O}_{12}\left(\varepsilon \sim 9 \times 10^{3}\right.$ at room temperature $(100 \mathrm{kHz}))$ by Zuo et al. [28], in contrast to the first report, $\varepsilon=409$, for pure $\mathrm{CdCu}_{3} \mathrm{Ti}_{4} \mathrm{O}_{12}[1]$. 

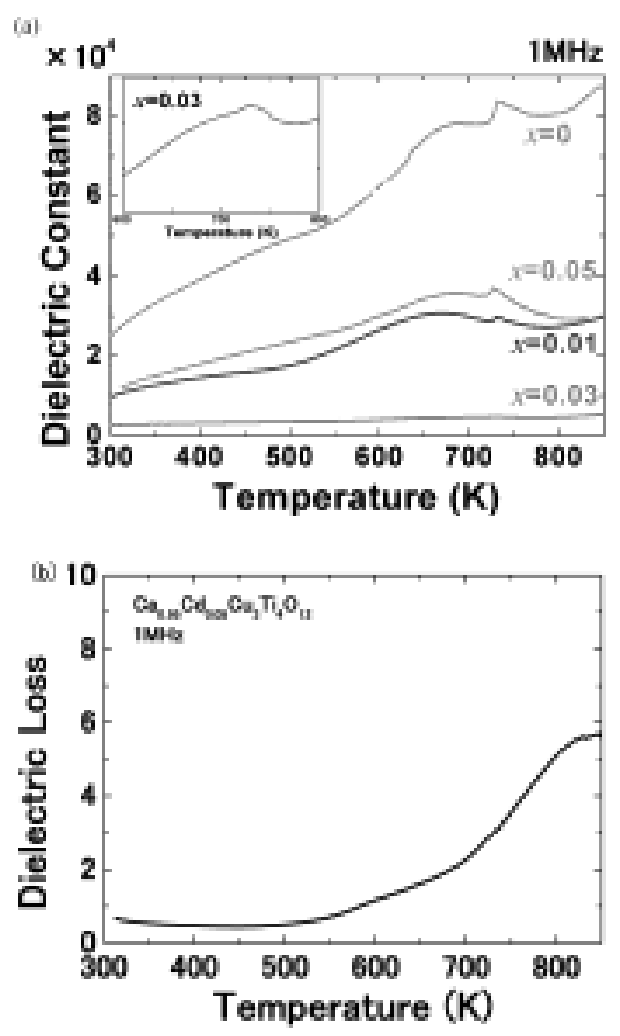

Figure 4. (a) Dielectric constant of Cd-doped ceramics, $\mathrm{Ca}_{1-x} \mathrm{Cd}_{x} \mathrm{Cu}_{3} \mathrm{Ti}_{4} \mathrm{O}_{12}$ with $x=0,0.01,0.03$ and 0.05 at 1 MHz. The inset is an expanded figure around $T_{1}$ for $x=$ 0.03. (b) Dielectric loss of $\mathrm{Ca}_{1-x} \mathrm{Cd}_{x} \mathrm{Cu}_{3} \mathrm{Ti}_{4} \mathrm{O}_{12}$ with $x=$ 0.05 at $1 \mathrm{MHz}$.

This evidence means that $\mathrm{CdCu}_{3} \mathrm{Ti}_{4} \mathrm{O}_{12}$ is also a member of high-dielectric materials.

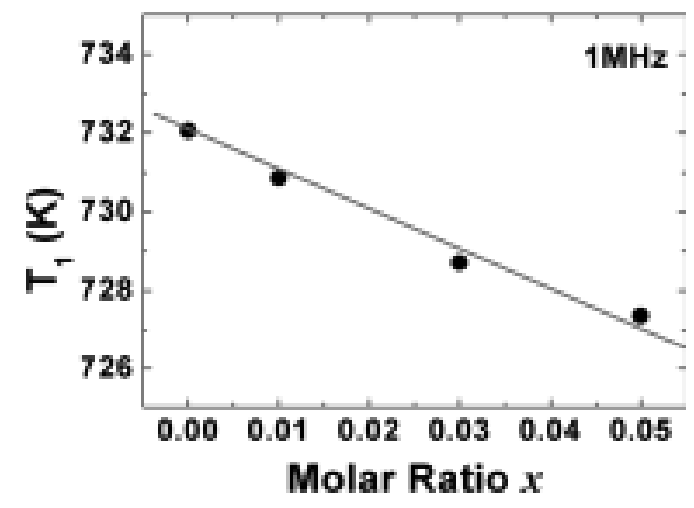

Figure 5. Molar ratio $(x)$ dependence of the transition temperature $\left(T_{1}\right)$ in $\mathrm{Ca}_{1-x} \mathrm{Cd}_{x} \mathrm{Cu}_{3} \mathrm{Ti}_{4} \mathrm{O}_{12}$ ceramics.

\section{DISCUSSION}

The chemical formula $\mathrm{CaCu}_{3} \mathrm{Ti}_{4} \mathrm{O}_{12}$ can be expressed as $4\left(\mathrm{Ca}_{1 / 4} \mathrm{Cu}_{3 / 4}\right) \mathrm{TiO}_{3}$ in the ideal perovskite $\mathrm{ABO}_{3}$ structure. The unit cell contains eight $\mathrm{TiO}_{6}$ octahedra. Owing to the presence of $\mathrm{Ca}$ and $\mathrm{Cu}$, the $\mathrm{TiO}_{6}$ octahedra are highly distorted in the framework of $\mathrm{O}-\mathrm{Ca}-\mathrm{O}$ and

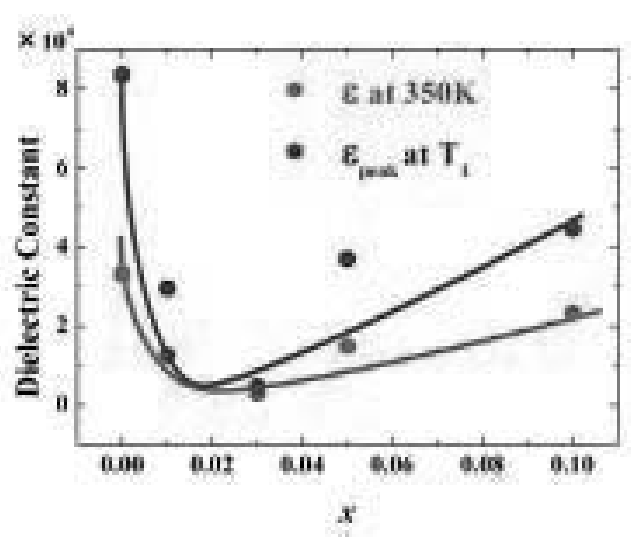

Figure 6. Dependence of dielectric constant at $350 \mathrm{~K}$ and $T_{1}$ on molar ratio $(x)$ in $\mathrm{Ca}_{1-x} \mathrm{Cd}_{x} \mathrm{Cu}_{3} \mathrm{Ti}_{4} \mathrm{O}_{12}$ at $1 \mathrm{MHz}$.

O-Cu-O.[29, 30] In typical perovskite ferroelectrics, the dipole moment induced by the distortion of $\mathrm{TiO}_{6}$ octahedron from its regular configuration plays an important role for the appearance of ferroelectricity.

$\mathrm{CaCu}_{3} \mathrm{Ti}_{4} \mathrm{O}_{12}$ exhibits the enormously high dielectric constant of the order of $10^{4}$ in both forms of single crystals, ceramics and thin films at room temperature. Cohen et al. [31] interpreted the giant dielectric constant of $\mathrm{CaCu}_{3} \mathrm{Ti}_{4} \mathrm{O}_{12}$ arising from spatial inhomogeneity of local dielectric response. Present study indicates that $\mathrm{CaCu}_{3} \mathrm{Ti}_{4} \mathrm{O}_{12}$ undergoes a phase transition at about 730 $\mathrm{K}\left(T_{1}\right)$. As the precise crystal structure of constituting atoms in $\mathrm{CaCu}_{3} \mathrm{Ti}_{4} \mathrm{O}_{12}$ above $T_{1}$ has not been clear at present, it may be probable that X-ray diffuse scattering behavior at high temperatures suggests an order-disorder motion between $\mathrm{Ca}$ and $\mathrm{Cu}$. Such motions of $\mathrm{Ca}$ and $\mathrm{Cu}$ are closely related to the large fluctuation of $\mathrm{TiO}_{6}$ octahedra, which allows the strong dipolar correlation as Jahn-Teller interaction. Whangbo and Subramanian explained the high dielectric constant in terms of its crystal structure, where the high dielectric property may arise from local dipole moments associated with off-center displacement of $\mathrm{Ti}$ ions, but the transition to a ferroelectric state is frustrated by the $\mathrm{TiO}_{6}$ octahedral tilt which is required to accommodate the $\mathrm{CuO}_{2}$ square planar coordination.[32] It may be probable that the present work is associated with such structural behavior at high temperatures.

Dielectric measurements of Cd-doped CCTO ceramics were studied. A new dielectric anomaly was found at a high temperature $\left(T_{1}\right)$, just as in pure CCTO. No drastic suppression of dielectric response could be observed by Cd-doping. $\mathrm{CdCu}_{3} \mathrm{Ti}_{4} \mathrm{O}_{12}$ is still a member of high-dielectric materials. Further studies of precise crystal structure below and above $T_{1}$ will be necessary to clarify the new phase transition in $\mathrm{CaCu}_{3} \mathrm{Ti}_{4} \mathrm{O}_{12}$.

\section{References}

[1] M. A. Subramanian, D. Li, N. Duan, B. A. Reisner and A. W. Sleight, J. Solid State Chem ., 151, 323 (2000).

[2] A. P. Ramirez, M. A. Subramanian, M. Gardel, G. 
Blumberg, D. Li, T. Vogt and S. M. Shapiro, Solid State Commun., 115, 217 (2000).

[3] M. A. Pires, C. Israel, W. Iwamoto, R. R. Urbano, O. Aguero, I. Torriani, C. Rettori and P. G. Pagliuso, Phys. Rev., B73, 224404 (2006).

[4] P. Lunkenheimer, R. Fichtl, S. G. Ebbinghaus and A. Loidl, Phys. Rev., B70, 172102 (2004).

[5] L. Chen, C. L. Chen, Y. Lin, Y. B. Chen, X. H. Chen, R. P. Bontchev, C. Y. Park and A. J. Jacobson, Appl. Phys. Lett., 82, 2317 (2003).

[6] T. T. Fang and H. K. Shiau, J. Am. Ceram. Soc., 87, 2072 (2004).

[7] I.-D. Kim, A. Rothschild and H. L. Tuller, Appl. Phys. Lett., 88, 072902 (2006).

[8] D. C. Sinclair, T. B. Adams, F. D. Morrison and A. R. West, Appl. Phys. Lett., 80, 2153 (2002).

[9] G. Zang, J. Zhang, P. Zheng, J. Wang and C. Wang, J. Phys., D 38, 1824 (2005).

[10] T. B. Adams, D. C. Sinclair and A. R. West, Phys. Rev., B73, 094124 (2006).

[11] R. K. Grubbs, E. L. Venturini, P. G. Clem, J. J. Richardson, B. A. Tuttle and G. A. Samara, Phys. Rev. B 72, 104111 (2005).

[12] S. Y. Chung, I. D. Kim and S. J. L. Kang, Nat. Mater., 3, 774 (2004).

[13] P. Lunkenheimer, V. Bobnar, A. V. Pronin, A. I. Ritus, A. A. Volkov and A. Loidl, Phys. Re v. B66, 052105 (2002).

[14] S. Krohns, P. Lunkenheimer, S. G. Ebbinghaus and A. Loidl, Appl. Phys. Lett., 91, 022910 (2007).

[15] Y. Zhu, J. C. Zheng, L. Wu, A. I. Frenkel, J. Hanson, P. Northrup and W. Ku, Phys. Rev. Lett., 99, 037602 (2007).

[16] B. Bochu, M. N. Deschizeaux, J. C. Joubert, A. Collomb, J. Chenavas and M. Marezio, J. Solid State Chem., 29, 291 (1979).

[17] M. A. Subramanian and A. W. Sleight, Solid State Sci., 4, 347 (2002).

[18] C. C. Homes, T. Vogt, S. M. Shapiro, S. Wakimoto, M. A. Subramanian and A. P. Ramirez, Phys. Rev. B67, 092106 (2003).

[19] J. J. Liu, C. G. Duan, W. G. Yin, W. N. Mei, R. W. Smith and J. R. Hardy, J. Appl. Phys ., 98, 093703 (2005).

[20] S. Y. Chung, S. Y. Choi, T. Yamamoto, Y. Ikuhara and S. J. L. Kang, Appl. Phys. Lett., 88, 091917 (2006).

[21] L. He, J. B. Neaton, M. H. Cohen and D. Vanderbilt, Phys. Rev. B65, 214112 (2002).

[22] L. Wu, Y. Zhu, S. Park, S. Shapiro, G. Shirane and J. Tafto, Phys. Rev. B71, 014118 (2005).

[23] A. Onodera, M. Takesada, K. Kawatani and S. Hiramatsu, Jpn. J. Appl. Phys., 47, 7753 (2008).

[24] A. Onodera and M. Takesada, Ferroelectrics, 379, 15 (2009).

[25] J. L. Zhang, P. Zheng, C. L. Wang, M. L. Zhao, J. C. Li and J. F. Wang, Appl. Phys. Lett., 87, 142901 (2005).

[26] E. A. Patterson, S. Kwon, C. C. Huang and D. P. Cann, Appl. Phys. Lett., 87, 182911 (2005).

[27] R. N. P. Choudhary and U. Bhunia, J. Mat. Sci., 37, 5177 (2002).

[28] R. Zuo, L. Feng, Y. Yan, B. Chen and G. Cao, Solid State Commun., 138, 91 (2006).

[29] S. M. Moussa and B. J. Kennedy, Mat. Res. Bull.,
36, 2525 (2001).

[30] E. S. Bozin, V. Petkov, P. W. Barnes, P. M. Woodward, T. Vogt, S. D. Mahanti and S. J. L. Billinge, J. Phys. Condens. Matter, 16, S5091 (2004).

[31] M. E. Cohen, J. B. Neaton, L. He and D. Vanderbilt, J. Appl. Phys., 94, 3299 (2003).

[32] M.-H. Whangbo and M. A. Subramanian, Chem. Mater., 18, 3257 (2006).

(Received December 25, 2009; Accepted January 31, 2010) 